\section{On Keeping Marine Organisms Alive in Small} Aquaria.

IN NATURE of November Io (p. 44), a contrivance is mentioned by the use of which the sea-water in a small aquarium can be kept in motion. The same kind of apparatus has been employed during the winter $1897-98$ in Kiel, for keeping Peridinea and Diatoms of the Plankton in a healthy condition. Prof. Geo. Karsten has described the apparatus used in the Wissenschaft. Meeresuntersuch. der Kommiss, z. wissenschaft. Untersuch. d. deutsch. Meere in Kiel und der Biolog. Anstalt a. Helgoland, vol. iii. part 2, March I898, p. 8. In this case a clinostatclockwork was used, and the plunger rose five times in three minutes. The bell-jar, serving as an aquarium, was very small, holding about $I^{\prime} 5$ litre. Ceratium and Skeletonema got on very well, the same plants dying off rapidly on being kept in water at rest.

Owens College, Manchester.

\section{THE NOVEMBER LEONIDS OF I898.}

VER

RY unfavourable weather was experienced all over the country at the middle of November, and the return of the Leonid meteors was very scantily observed. At many stations no observations whatever were possible between November 13 and 16 , while at other places only one of these nights was partially clear. As a result of the bad atmospheric conditions, very few meteors have been recorded. But it seems certain, from a comparison of the fragmentary observations obtained at various places, that, apart from the unfavourable influence of the weather, the meteoric shower did not nearly answer expectation. In fact, the number of meteors visible appears to have scarcely exceeded the average number that may be counted on an ordinary mid-November night. It is true that the observations did not cover the whole of the three nights of November 14, 15 and 16, and were, moreover, effected in most cases under circumstances little calculated to ensure successful results. But making every allowance for the difficulties encountered, the feeble character of the shower is still significant, and proves that the earth in recently crossing the node of Tempel's comet of 1866 , did not encounter the denser part of the meteoric stream, but a very attenuated region far in advance of the associated comet. Indeed, the recent display appears to have been scarcely richer than those of 1879 and 1888 , when the comet was not a great distance from its aphelion. Of course, the real shower may have occurred in the daytime, but it would scarcely escape recognition in America or some other distant part, for observers all over the world are keenly alive to the attractions and the importance of the Leonid display, and have been on the alert to witness it.

Descriptions of the recent shower from the United States are not dissimilar to those from our own country. Of course, we cannot rely upon the exaygerated statements published in some of the American newspapers, or sent home by the New York correspondents of certain English journals. One of the latter, writing on November I5, says: "Astronomers throughout the United States watched the shower of Leonid meteors, which appeared between midnight and five o'clock this morning. Many of the meteors made brilliant flashes across the sky, and left fiery trains. One meteor in Orion lit up the entire city of New York at about one o'clock in the morning, and fell hissing, the sound indicating its close proximity." More trustworthy accounts from astronomical observers at the Lick Observatory, Mount Hamilton, the Princeton Observatory, and others at Richmond, Virginia, agree that the late display was a disappointing one, the meteors seen being neither numerous nor brilliant.

With regard to observations made in this country, the writer has received reports from London, Oxford, Bridport, Yeovil, Cardiff, Chester, Loughton (Essex), CirenNO. I 517 , vOL. 59] cester, Stone (Staffs.), Leeds, Southport, Belfast, Dumfries, and several other places. A few quotations from these may perhaps be interesting :-

Belfast. - A watch was maintained on November 12 to I 5 h. 3om., but no Leonids observed. On the following night (I $\left.3^{\text {th }}\right)$, to the same time, six meteors were recorded, and of these three may have been Leonids. On November 14, the sky was overcast to I6h. $40 \mathrm{~m}$. ; then it partly cleared ; but there was a good deal of nist, and the stars shone very dimly. Between $16 \mathrm{~h}$. 40m. and I $7 \mathrm{~h}$. $15 \mathrm{~m}$. the observer saw ten fine Leonids; but the sky became cloudy again, and observations were discontinued. The shower was regarded as a fairly strong one under the conditions, and the maximum appeared to be at about I $7 \mathrm{~h} .-\mathrm{W}$. H. Milligan.

Southport.-Observations were made at the Meteorological Observatory on November I4, I3h. 30m. to I $7 \mathrm{~h}$. 3om., and the following were the hourly number of meteors (nearly all Leonids) noticed by one observer :-

$$
\begin{aligned}
& \text { h. m. h. m. } \\
& \text { I3 } 30 \text { to I4 } 30=\text { I } 5 \text { meteors. } \\
& \text { 14 } 30 \text { to I5 } 30=10 \quad,, \\
& \text { I5 } 30 \text { to } 1630=3 \quad, \\
& \text { I6 } 30 \text { to I7 } 30=2,
\end{aligned}
$$

The meteors were small, not one being brighter than a ist mag. star. The scarcity of meteurs, only five being seen between $15 \mathrm{~h} .30 \mathrm{~m}$. and $17 \mathrm{~h}$. 30m., is remarkable.- J. Baxendale.

Yeovil.--On November I4 the sky was clear, but only two or three meteors were remarked in the two hours between I 3 h. and I 5 h. -Rev. T. E. R. Phillips.

Cirencester. - Weather clear during the whole night of November I4, and only a little fog at low altitudes. Observations were made from a window facing E., between I Ih. $45 \mathrm{~m}$. and I $2 \mathrm{~h}$. $50 \mathrm{~m}$., but no meteors were seen. The sky seemed unaccountably light.-Miss E. Brown.

Gateshead.--On November I3, between Ioh. and I5h., the atmosphere was favourable, and observations were made at short intervals, but no meteors were seen.Dr. A. W. Blacklock (English Mechanic).

Northants. - On November I4, from midnight to I $5 \mathrm{~h}$., a watch was kept with results almost nil.. The sky was, however, partially veiled with clouds through which only a few stars could be seen. There was a very brilliant meteoric flash at $13 \mathrm{~h}$. $55 \mathrm{~m} .-\mathrm{F}$. H. Wright (English Mechanic).

Bristol.--On November 12 the clouds passed off at I 5 h., and the sky was watched intermittently until i $7 \mathrm{~h}$. Only seven meteors were seen. There was no sign of radiation from Leo. At $16 \mathrm{~h} .4 \mathrm{~m}$. the sky was illuminated, probably by the outburst of a large meteor in a region of the heavens hidden to the observer. The nights of November I 3 to I 9 were all overcast, and no observations could be obtained.-W. F. D.

Chester.-On November I6, between Ioh. and I3h., six plates were exposed for $30 \mathrm{~m}$. each, but no meteor trails were secured. The meteors appeared to be scarcer than on any ordinary night. At $\mathrm{I} 2 \mathrm{~h} .8 \mathrm{~m}$. a Leonid of the apparent brightness of Mars was seen, and with the exception of a small, swift Perseid nothing else was recorded. -F. W. Longbottom.

The remainder of the reports are stories of failure in consequence of the weather. At many places a series of dense fogs occurred just at the important time. In spite of these drawbacks, however, the fact remains that at certain stations on November 15 a clear sky invited observation, but presented very few meteors. It is true that Mr. Milligan saw some brilliant ones in the hazy sky of November 14, 16h. 30m. to $17 \mathrm{~h}$. $15 \mathrm{~m}$., and that the observed maximum of the "shower" seems to have occurred at nearly the same time as last year. But the phenomenon, so far as it was observed, was quite of minor character, and observers who saw nothing what- 
ever, owing to the weather, may take comfort in the reflection that they lost very little. Of course, further observations may come to hand from distant places where the stars shone and meteors fell. If so, we may possibly have to modify our present ideas; but from the materials now before us, we can only draw the following conclusions :-

(I) The state of the atmosphere generally was very unfavourable for the observation of meteors.

(2) The number of meteors which appeared was small and never at any time formed a display of special richness.

(3) The earth was too far in advance of the cometary nucleus to encounter the denser region of the meteoric stream.

But the observations obtained this year, if of a negative character, and very discouraging from an observational point of view, will yet be important as affording evidence of the tenuity of that section forming the vanguard of the stream.

The meteoric observer, disappointed as he has been in 1897 and 1898, may yet look forward with every confidence to the brilliant displays which will mark the years 1899,1900 and 1901 .

W. F. DENNING.

\section{NOTES.}

IT has already been announced that in connection with the Royal Society the Colonial Office has instituted a Commission to investigate the subject of tropical malaria. We are now informed that the medical officers selected for the work in Africa are Dr. D. Daniels, of the Colonial Office Medical Service, Dr. Stevens, and Dr. Christopher. Dr. Daniels has sailed for India in order to make himself acquainted with the recent observations of Surgeon-Major Ronald Ross, of the Indian Medical Service, connecting the spread of malarial disease with certain species of mosquitoes. The two other gentlemen referred to will go direct to Nyasaland, in British Central Africa, to study malarial disease in that locality; and will eventually be joined by Dr. Daniels. With the knowledge acquired in a comparatively temperate climate, where, however, fever has of late years been peculiarly fatal, the three medical officers will, at a later date, visit West Africa, possibly on the Niger. The Royal Society proposes to contribute towards the expense of the investigation, the British Government, through the Foreign and Colonial Offices, finding the remainder. It is estimated that the investigations will occupy about two years, and reports will be submitted from time to time to a Committee nominated jointly by the Royal Society and the Secretary of State.

IT will be remembered that the late Mr. Alfred Nobel left almost the whole of his fortune to be converted into an international fund for the advancement of scientific research (see NATURE, vol. 1v. p. 232). The bequest gave rise to a dispute, which we are glad to learn has been settled by a compromise between the contesting parties. The relatives of the deceased will receive $3,800,000$ Swedish kronor, or about 2I I, $000 l$., so that there still remains for the prizes the sum of $25,000,000$ kronor, or nearly $\mathrm{I}, 400,000 /$. The income, computed at the rate of 3 per cent., will make the five prizes worth 150,000 kronor, or $8300 l$. each. It is expected that the compound interest during the time, which will necessarily be long, that will elapse before the prizes can be awarded, will increase the capital so as to cover the cost of managing the funds and the work entailed in properly distributing the prizes. It will be remembered that these prizes are to be awarded annually to persons making the most important discoveries in physics, chemistry, physiology or medicine. There is also to be a prize for the best literary contribution upon the subject of physiology

NO. I 517 , vOL. 59] or medicine, and also one for any person who has achieved the most or done the best things looking towards the promotion of the cause of peace throughout the world.

M. A. Michel LÉvy has been elected a corresponding member of the Berlin Academy of Sciences.

WE regret to see the announcement of the death of Dr. James I. Peck, assistant professor of biology in Williams College, and assistant director of the Marine Biological Laboratory at Woods Holl.

THE first competition offered by the Nansen Fund, which was established soon after the return of the Fram in 1896 , has just been advertised. The subject is a thorough work in embryology based on original investigation, and the amount of the prize is I 500 kroner (about $80 l$.) The result will be announced at the annual meeting of the Christiania Academy of Science, May 3, I900.

The Christmas Course of Lectures, specially adapted to young people, at the Royal Institution, will be delivered this year by Sir Robert Stawell Ball, F.R.S. The subject will be "Astronomy," and the lectures (which will be illustrated by models and the optical lantern) will deal with the sun, the moon, the inner planets, the great planets, shooting-stars, and new methods. The first lecture will be delivered on Tuesday, December 27 , at three o'clock, and the remaining lectures on December 29 and 31 , and on January 3, 5 and 7, 1899 .

THE death is announced at Paris, at the age of seventy-four, of M. J. N. Raffard, distinguished for his inventions and papers on science and technology. His inventions include governors for engines, several ingenious dynamometers, and many other appliances; he was the first to construct in Paris an electric tram-car worked by accumulators. He was a member of the Committee of Mechanical Arts of the Paris Société d'Encouragement, and also of the Editorial Committee of the Revue de Mécanique.

Sir George Baden-Poweil, K.C.M.G., whose death, at the comparatively early age of fifty-one, we regretfully announce, took an active interest in scientific affairs, and in many ways assisted the advancement of natural knowledge. He was the son of the Rev. Prof. Baden-Powell, the Oxford geometrician and geologist. In 1896 , he rendered a most valuable service to astronomy by conveying a small party of observers to Novaya Zemlya to make observations of the total eclipse of the sun. It will be remembered that on account of unfavourable weather the eclipse was not observed in Norway, where most of the British observers were situated; but, fortunately, better conditions prevailed at Novaya Zemlya, and excellent photographs were obtained of eclipse phenomena. The total failure of the British expeditions was thus saved by Sir George Baden-Powell's timely aid. His death will be mourned by many friends in the scientific world.

Sir John Fowler, K.C.M.G., Bart., the distinguished engineer, died on Sunday, at the age of eighty-one. His name is associated with some of the greatest engineering triumphs of this century. He was responsible for the design and construction of the Underground (Metropolitan) Railway, and carried out the scheme successfully in the face of gigantic difficulties and great opposition. He was engineer-in-chief of the Forth Bridge, which he designed in association with Sir Benjamin Baker, and he planned and commenced in 1875 the Sudan Railway to Khartum, now on the point of completion. It was in consideration of his work for the benefit of Egypt that in 1885 the Queen conferred upon him a Knight Commandership of St. Michael and St. George. For his services in connection with the Forth 